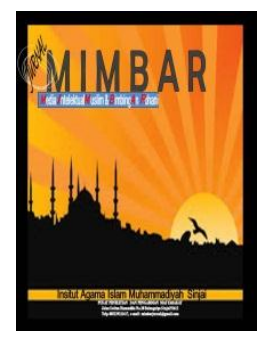

\title{
MIMBAR
}

Jurnal Media Intelektual Muslim dan Bimbingan Rohani

Volume 6, No. 1, 2020

P-ISSN: 2442-3217

E-ISSN: 2716-3806

Homepage : http://journal.iaimsinjai.ac.id/indeks.php/mimbar

\section{KONSELING SPIRITUAL PADA PENDERITA GANGGUAN MENTAL DI PONDOK PESANTREN REHABILITAS SALAFIYAH SYAFI'IYAH NASRUN MINALLAH YOGYAKARTA}

\author{
Indra ${ }^{1}$ \\ ${ }^{1}$ Universitas Islam Negeri Sunan Kalijaga, Yogyakarta \\ Email:pondokkecil93@gmail.com
}

\begin{abstract}
Abstrak
Penelitian ini dilaksanakan di Pondok Pesantren Rehabilitas Salafiyah Syafi'iyah Nasrun Minallah Yogyakarta. Tujuan penelitian ini adalah untuk mengetahui nuansa konseling spiritual yang diberikan pada santri pondok pesantren yang mengalami gangguan mental yang sumbernya dari kesurupan, gangguan jin, dan sihir. Adapun metode yang digunakan terkait dengan penelitian ini adalah penelitian lapangan (field research), yaitu penelitian yang pengumpulan datanya dilakukan dilapangan untuk melakukan pengamatan terhadap suatu fenomena dalam suatu keadaan alamiah dengan observasi dan wawancara. Hasil penelitian lapangan yang dilaksanakan terdapat bahwa metode dalam menangani seseorang yang mengalami gangguan jin, kesurupan, dan sihir sehingga berdampak pada gangguan mental seorang yaitu melalui terapi ruqyah dengan dzikir dilaksanakan oleh satri pagi dan sore (AlMa'tsurat). Terapi ruqyah yang merupakan bagian dari psikoterapi Islam memberi dampak pada kesembuhan dari gangguan mental dan menunjang kualitas spiritual seseorang.
\end{abstract}

Kata Kunci: Konseling, Spiritual, dan Gangguan Mental

\section{Pendahuluan}

Manusia makhluk ciptaan Tuhan paling sempurna. Memiliki akal yang membedakan dengan makhluk lainnya. Dengan akalnya manusia bisa memilih untuk berbuat kebaikkan atau keburukkan. Dengan agama dan spiritual manusia juga bisa mecapai kesempurnaan batiniahnya.

Pertumbuhan dan perkembangan individu merupakan suatu proses yang berjalan seumur hidup. Dimensi pertumbuhan dan perkembangan meliputi fisiologis, psikologis, sosial, kultural dan spiritual. Pada perjalanan pertumbuhan dan perkembangan setiap individu akan dihadapkan dengan berbagai masalah yang tidak dapat dielakkan seperti masalah kesehatan, masalah sakit dan penyakit (Iwan Ardian).

Pada umumnya spiritual merupakan identitas fundamental individu yang merupakan puncak capaian perkembangan dimana individu mampu mencari makna tujuan dan hakikat hidup (Ardiansyah, 2018). Spiritual juga merupakan konsep yang luas dengan berbagai dimensi dan perspektif yang ditandai adanya perasaan keterikatan 


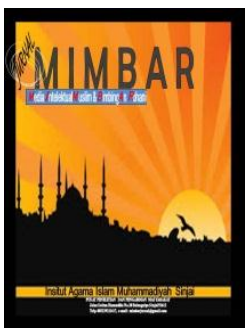

kepada sesuatu yang lebih besar dari diri sendiri, yang disertai dengan usaha pencarian makna dalam hidupnya atau dapat di jelaskan sebagai pengalaman yang bersifat universal dan menyentuh (Iwan Ardian).

Namun, sejalan dengan pertumbuhan manusia tidak dapat terpungkiri adanya berbagai permasalahan yang berkaitan dengan psikologisnya, seperti kesehatan mental yang dikarenakan banyaknya problem hidup. Menurut Surya (Perdana Akhmad, 2005), mental seseorang ditentukan oleh beberapa kondisi yang mempengaruhinya, yaitu kepribadian, kondisi fisik, kematangan dan perkembangan, kondisi psikologis, lingkungan dan keberagamaan.

Kesehatan mental atau kesehatan jiwa juga merupakan aspek penting layaknya kesehatan fisik dalam mewujudkan kesehatan secara menyeluruh. Demikian World Health Organization (WHO) mendefenisikan kesehatan mental, bahwa "health as a state of complete physical, mental and social well-being and not merely the absence or infirmity" (Ayuningsita, et al, 2018). Bahwa kesehatan merupakan kesejahteraan baik, fisik, mental, maupun sosial.

Kesehatan mental masih menjadi suatu permasalahan kesehatan yang signifikan di dunia, termasuk di Indonesia. Pesatnya pertumbuhan dan beban hidup ditanah air menjadi pemicu bertambahnya penderita gangguan mental. Beban penyakit mental di Indonesia terhitung cukup besar. Sekitar 1 juta pasien gangguan jiwa berat dan 19 juta pasien gangguan jiwa ringan tercatat dalam Riskesdas 2014(Sya'hroni \& Khusnul Khotimah, 2018). Data rutin Dinas Kesehatan (Dinkes) Yogyakarta pada tahun 2015 telah menunjukkan angka sebesar 10.993 orang dengan gangguan jiwa dan tahun 2016 jumlah tersebut menjadi 10.554 belum termasuk kabupaten Sleman (Dinkes DIY, 2017).

Berdasarkan data diatas terkait dengan masalah kesehatan mental banyak kemudian yang dilakukan dalam mengatasi gangguan mental tersebut, baik itu secara medis maupun non-medis. Secara non-medis yakni mengarah pada pengobatan tradisional dan spiritual dengan kembali pada al-Qur'an dan hadits. Thomas G. Plante (Sya'roni \& Khotima, 2018), bahwa dalam penelitiaan mengenai perilaku dan 
keyakinan agama dan spiritual pada hasil kesehatan baik mental maupun fisik, dapat dilihat dari banyaknya minat terhadap masalah spiritualitas dan kesehatan.

Masalah gangguan mental banyak dipengaruhi oleh berbagai aspek kehidupan manusia, seperti halnya yang terjadi di PP Rehabilitas Nasrun Minallah. Pada Pondok Pesantren tersebut menarik perhatian penulis untuk kemudian menjadikan sebagai objek penelitian salah satunya, bahwa orang yang menjadi santri merupakan orang yang mengalami ganggguan jin, kesurupan, dan sihir.

Dengan demikian penanganan yang kemudian dilaksanakan di PP Rehabilitas Nasrun Minallah yakni penanganan secara spiritual melalui terapi ruqya dengan kembali pada Al-Qur'an dan hadis Rasulullah. Terapi ruqyah sangat memungkinkan dalam penanganan atau pengobatan pada penderita gangguan menta. Sebagaimana dalam penelitian (Susanto, 2014), bahwa hal-hal ghaib menjadi pemicu munculnya gangguan mental seseorang seperti misalnya, kesurupan, gangguan jin, dan sihir sehingga mempengaruhi pikiran, pola perilaku, dan tindakan seseorang bahkan spiritualnya.

\section{Metode}

Penelitian ini adalah penelitian lapangan (field research), yaitu penelitian yang pengumpulan datanya dilakukan dilapangan untuk melakukan pengamatan terhadap suatu fenomena dalam suatu keadaan alamiah. Penelitian ini menggunakan deskriptif kualitatif, yakni penelitian yang digunakan untuk memahami fenomena mengenai apa yang dilakukan subjek penelitian, seperti perilaku, ucapan, dan tindakan dengan cara deskripsi dalam bentuk kata dan bahasa, dengan cara penggalian data dari lapangan secara mendalam luas dan menyeluru (M. Hafidz Ridho, 2018). Sumber data penelitian ini yakni, Ust. Yoyo selaku pimpinan Pondok Pesantren Rehabilitas Salafiyah Syafi'iyah Nasrun Minallah sebagai sumber data primer pada penelitian ini dengan pendekatan konseling spiritual dalam penanganan gangguan mental pada santri yang mengalami kesurupan, gangguan jin, dan sihir.

Teknik pengumpulan data berupa observasi langsung dilapangan dengan pencatatan atas kejadian-kejadian yang dilakukan oleh sumber data (Amani, 2018). Kemudian teknik wawancara dengan pertanyaan bebas namun tidak lepas dari data yang dibutuhkan, adapun objek wawancara pada penelitian ini yakni melibatkan langsung 


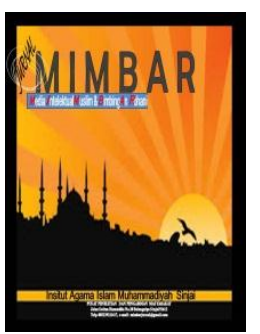

pimpinan PP Rehabilitas Nasrun Minallah oleh Ust. Yoyo. Selanjutnya adalah teknik dokumentasi yakni catatan-catatan peristiwa yang telah berlalu seperti, tulisan, gambar, dan data sekunder berupa, buku, jurnal, internet, dan dukumen lain.

\section{Hasil dan Pembahasan}

Sesuai dengan perkembangan kajian keilmuan defenisi bimbingan konseling juga turut berkembang tanpa meninggalkan esensinya dengan pemberian bantuan (helping relationship). Konseling menurut Prayitno adalah proses pemberian bantuan kepada individu yang sedang mengalami suatu masalah yang bermuarah pada teratasinya masalah yang dihadapi individi atau klien (Prayitno \& Erman, 2009). Kegiatan bimbingan dan konseling merupakan keterampilan yang pada intinya mengajak, membimbing dan mengarahkan klien kembali pada fitrahnya (M. hafidz Ridho, 2018).

Salah satu ruang lingkup dalam bimbingan konseling adalah konseling spiritual. Mulyani Rina mengatakan bahwa konseling spiritual adalah proses pemberian bantuan kepada individu agar memiliki kemampuan untuk mengembangkan fitrahnya sebagai mahluk beragama (homo religious), berperilaku sesuai dengan nilai-nilai agama, dan mengatasi masalah-masalah kehidupan melalui pemahaman, keyakinan dan praktikpraktik ibadah ritual agama yang dianutnya (Annisa, dkk, 2017). Berdasarkan hal tersebut, artinya bahwa bimbingan spiritual terdapat intrevensi Tuhan dalam kehiduapan manusia untuk menolongnya dalam mengatasi masalah dan melakukan suatau perubahan agar menjadi lebih baik.

Secara eksplisit, Piedmont memandang spiritual sebagai rangkaian karakteristik motivasional (motivational trait), kekuatan emosional umum yang mendorong, mengarahkan, dan memilih beragam tingkah laku individu. Kemudian sebagai usaha individu untuk memahami sebua makna yang luas akan pemaknaan hidup individu (M. Hafidz Ridho, 2018). Artinya bahwa setiap individu sadar akan kematian. Dengan demikian, mencobah membangun pemahaman akan tujuan dan makna kehidupan yang sedang dijanin dan akan dihadapi.

Sementara itu, dimensi spiritualitas dari paham dan penghayatan keberagamaan pada dasarnya merupakan sebuah perjalanan kedalam diri manusia itu sendiri. Setiap 
manusia senantiasa merindukan kedamaian, kebahagian, hubungan cinta kasih dan selalu ingin berdampingan dengan yang Maha Kasih (Fatma, 2012).

Seperti halnya setiap individu menginginkan jiwa yang sehat atau mental yang sehat. Menurut Surya (1985), orang yang mentalnya sehat tidak hanya terhindar dari gangguan atau penyakit mental, tetapi tercemin dalam kondisi pribadi secara keseluruhan. Jadi sehat tidaknya mental seseorang dilihat dari seberapa jauh aspekaspek mentalnya terorganisasikan sedemikian rupa sehingga mencerminkan suatu keadaan kesehatan pribadi (Pedana, 2005).

Konseling spiritual merupakan proses penyembuhan atau pengobatan suatu penyakit baik mental, spiritual, moral maupun fisik dengan kembali pada pedoman hidup manusia yakni, al-Qur'an dan as-sunnah Rasulullah. Secara empiris melalui bimbingan dan pengajaran Allah swt, malaikat dan rasul-Nya (Rahayu, 2009).

Sebagaimana fungsi dan manfaat pembacaan ayat-ayat al-Qur'an sebagai berikut adalah:

a. Pemberian Nasehat

Pembacaan ayat-ayat al-Qur'an dalam rangka pemberian wejangan, bimbingan dan nasehat tentang berbagai macam persoalan, problematika kehidupan manusia dan lingkungannya (Hamdani, 2004). Demikian pula yang di laksanakan ole ust. Yoyo bahwa, langkah awal yang diberikan pada pasien yang mengalami gangguan mental akibat ganggua jin atau kesurupan yakni melalui shalat dan memberikan berbagai nasehat dan menanamkan kesiapan dan keyakian pada pasien untuk melangkah ke tahap selanjutnya. Spirtualisasi shalat yang ditinjau dari kesehatan mental, bahwa dalam shalat terjadi hubungan rohani atau spiritual antara manusia dengan Allah. Dalam suasana shalat yang khusyuk seseorang dapat memperoleh ketenangan jiwa (al-nafs almuthama'innat), karenanya tumbuh rasa kedekatan diri pada Allah dan memperoleh ampunan-Nya (Yahya, 1994).

b. Tindakan Pencegahan dan Perlindungan

Dalam proses pencegahan dan perlindungan dengan senangtiasa memanjatkan do'a agar dapat terhindar dan terlindungi dari berbagai masalah, musibah, dan bencana yang demikian dapat mengganggu keutuhan dan eksistensi kejiwaan (mental) 


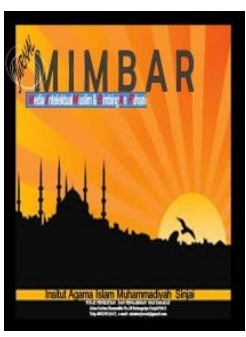

(Hamdani, 2004). Tindakan perlindungan dan pencegahan demikian dilaksanakan dengan cara berdzikir terhadap pasien yang mengalami gangguan jin dan hal-hal gaib lainnya. Dengan dzikir seseorang dapat memperoleh kecintaan dari Allah dan ketenangan jiwa, apabila dilakukan dengan benar dan penuh keyakina atau dalam artian khusyuk, serta meningkatkan kualitas spiritual dan kematangan pribadi (Yahya, 1994). c. Tindakan Pengobatan dan Penyembuhan

Meberikan pengobatan atau penyembuhan terhadap penyakit kejiwaan (mental) (Hamdani, 2004). Dalam hal ini disebut dengan pengobatan melalui teknik ruqyah yang dilaksanakan oleh ust. Yoyo, menurtutnya proses terapi ruqyah menggunakan ayat-ayat al-Qur'an dengan membaca dan mendengarkan secara keseluruahan atau dalam ayatayat tertentu yang berhubungan dengan gangguan atau penyakit mental yang akibatnya dari hal yang ghaib seperti gangguan jin dan kesurupan yang pada kenyataanya di alami oleh santri di PP Rehabilitas Nasrun Minallah.

Mengobati seseorang yang mengalami gangguan mental adalah dengan kembali pada al-Qur'an dan hadits Rasulullah. Al-Qur'an merupakan sebuah kitab suci dan petunjuk yang diturunkan Allah sebagai sumber pertama dan utama ajaran Islam. AlQur'an berbicara rasio dan kesadaran manusia. Selain itu Al-Qur'an menunjukkan kepada manusia jalan terbaik dalam kehidupan pribadi maupun sosial.

Terapi ruqyah yang merupakan bagian dari psikoterapi telah di terapkan dalam masyarakat Islam sebagaimana hal ini telah dilaksanakan pada PP Rehabilitas Nasrun Minallah yang dikenal dengan ruqyah syar'iyyah. Dewasa ini, ruqyah syar'iyyah merupakan suatau upaya penyembuhan yang dilaksanakan dengan memohon kapada Allah akan kesembuhan baik secara personal dan orang lain dengan membaca ayat-ayat al-Qur'an dan hadits shahih Rasulullah yang berkenang dengan penyakit yang dialami oleh seorang muslim (Sya'roni \& Khusnul Khotimah, 2018).

\section{Kesimpulan}

Berdasarkan hal-hal diatas yang menjelaskan bahwa gangguan mental yang berdampak pada emosi, pikiran dan perasaan terhadap seseorang yang di pengaruhi oleh adanya gangguan psikis dari adanya gangguan jin, kesurupan dan sihir. Sehingga spiritual seseorang menjadi terganggua pula. Pada PP Rehabilitas Nasrun Minallah, 


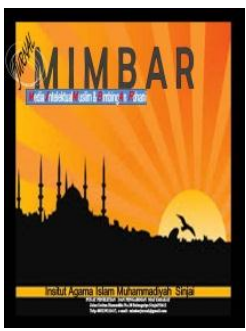

memberikan bimbingan spiritual pada pasien (santri), yang penerapannya melalui terapi ruqyah dan metode lain dalam pencegahan dan penanganannya yakni, sholat dengan tepat waktu, berdzikir pagi dan sore, dan pembacaan ayat-ayat suci al-Qur'an. Dengan lantunan ayat-ayat suci yang di terima otak melalui telinga yang menghasilkan suatu getaran yang berdampak positif. Sehingga mempengaruhi kinerja pada otak dan memulihkan adanya gangguan mental, termasuk emosi, pikiran dan perasaan yang tak menentu. Maka dapat disimpulkan bahwa konseling spiritual pada pasien gangguan mental di PP Rehabilitas Nasrun Minallah, melalui metode terapi ruqyah memberi dampak yang menunjang kesembuhan pada penderita gangguan jin dan sihir.

\section{Daftar Pustaka}

Bakran Hamdani Adz-Dzaky. (2004). Konseling dan Psikoterapi Islam. Jogjakarta; AlManar.

Jaya Yahya. (1994). Spiritualisasi Islam dalam Menumbuhkan Kepribadian dan Kesehatan Mental”. Jakarta; CV Ruhama.

Prayitno \& Amti Erman. (2009). Dasar-Dasar Bimbingan dan Konseling. Jakarta; Rineka Cipta.

Rahayu T Iin. (2009). Psikoterapi "Perspektif Islam dan Psikologi Kontemporer". Malang; UIN Malang Pers.

Akhmad Pedana. (2005). "Terapi Ruqyah Sebagai Sarana Mengobati Orang Yang Tidak Sehat Mentali” Jurnal Psikologi Islam, volume 1, nomor 1.

Amani. (2018). "Peran Guru Bimbingan dan Konseling dalam Memotivasi Belajar Siswa SMPN 15 Yogyakarta" Hisbah: Jurnal Bimbingan Konseling dan Dakwah Islam, volume 15, nomor 1, Juni.

Ardian Iwan. "Konsep Spiritual dan Religiusitas (Spritual and Religios) dalam Konteks Keperawatan Pasien Diabetes Melitus Tipe 2" Nurscopes; Jurnal Keperawatan dan Pemikiran Ilmiah.

Ardiansyah. (2018). "Upaya Bimbingan Konseling Nilai dan Spiritual Terhadap Transgender di Yogyakarta”. Jurnal Ilmiah Counsellia; volume 8, nomor 2, November. 


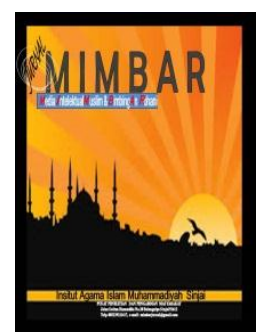

MIMBAR

Jurnal Media Intelektual Muslim dan Bimbingan Rohani

Volume 6, No. 1, 2020

P-ISSN: 2442-3217

E-ISSN: 2716-3806

Homepage : http://journal.iaimsinjai.ac.id/indeks.php/mimbar

Nida Fatma Lili Khoirun. (2012). "Peran Kecerdasan Spiritual Dalam Pencapaian Kebermaknaan Hidup", Jurnal Konseling Religi; volume 3, nomor 1, Januari.

Ridho Muhammad Hafizh (2018). “Bimbingan Konseling Spiritual Terhadap Pasien Rehabilitas Napza”. Jurnal Studia Insania; Vol. 6, No. 1 Mei.

Subrotol Annisa, dkk. (2017). "Pendekatan Koseling Spritual Sebagai Alternatif Pencegahan Prilaku Bulling (Kekerasan)". Prosiding SNBK (Seminar Nasional Bimbingan Konseling), volume 1, nomor 1, Mei.

Susanto Dedi. (2014). "Dakwah melalui Layanan Psikotrapi Ruqyah Bagi Pasien Penderita Kesurupan”. Jurnal Konseling Religi; Bimbingan Konseling Islam, volume 5, nomor 2 .

Yantiek Ermi. "Kecerdasan Emosi, Kecerdasan Spiritual, dan Perilaku Prososial Remaja”. Jurnal Psikologi Indonesia, Vol.3, No.01.

Ayuningsita et al. (2018). "Analisis Situasi Kesehatan Mental Pada Masyarakat di Indonesia dan Strategi Penanggulangannya”. Jurnal Ilmu Kesehatan Masyarakat, Vol. 1, No. 10 (Maret 2018).

Sya'roni \& Khusnul Khotimah. (2018). “ Terapi Ruqyah dalam Pemuliahan Kesehatan Mental”, Journal of Islamic Guidence and Counseling, Vol. 2, No. 1, Juni.

Dinas Kesehatan Yogyakarta, diakses pada tanggal 19 desember 2019 lihat juga di https://nasional.republika.co.id/berita/nasional/umum/17/07/20/otcmoo327mengapa-kasus-gangguan-jiwa-di-yogyakarta-tinggi 